\title{
Environmental Policy and Pollution Dynamics in an Economic Growth Model
}

\author{
Weibin Zhang \\ Ritsumeikan Asia Pacific University, Beppu-shi, Japan \\ E-mail:wbz1@apu.ac.jp \\ Received April 26, 2011; revised May 29, 2011; accepted June 13, 2011
}

\begin{abstract}
The purpose of this paper is to study dynamic interactions among capital accumulation, environmental change and labor distribution. We try to synthesize the growth mechanism in the neoclassical growth theory and the environmental dynamics in traditional models of environmental economics within a comprehensive framework with an alternative approach to household behavior. We build a model which describes a dynamic interdependence among physical accumulation, environmental change and division of labor under perfect competition with environmental taxes on production, wealth income, wage income and consumption. We simulate the model to demonstrate existence of equilibrium points and motion of the dynamic system. The simulation demonstrates some dynamics which can be predicted neither by the neoclassical growth theory Solow model nor by the traditional economic models of environmental change.
\end{abstract}

Keywords: The Environmental Kuznets Curve, Environmental Tax, Economic Growth, Capital Accumulation, Labor Distribution

\section{Introduction}

The purpose of this study is to study interactions between environmental change and economic growth. In recent years environmental issues have received more attention than ever. Global warming threatens living conditions of mankind and local environmental catastrophes are daily reported in TVs. It is challenging for economists to explain economic mechanisms and consequences of environmental changes. Environmental issues have increasingly caused attention in the literature of economic growth and development (see [1-3]). As mentioned by [4], one can find three effects that are important in explaining the level of environmental pollution and resource use. The three effects are: 1) increases in output tends to require more inputs and produce more emissions; 2) changes in income or preferences may lead to policy changes which will affect production and thus emission; and 3) as income increases, the economic structure may be changed which will causes changes in the environment (see [5-7]). It is argued that the net effect of these effects tends to result in the environmental Kuznets curve. Kuznets [8] postulated that economic growth and income inequalities follow an inverted U-curve. The environmental Kuznets curve refers to the same relation between environmental quality and per capita income. A recent survey on the economic models for the curve is given by [7]. Nevertheless, a large number of empirical studies on the environmental Kuznets curve for various pollutants find different relations - for instance, inverted U-shaped relationship, a U-shaped relationship, a monotonically increasing or monotonically decreasing relationship - between pollution and rising per capita income levels (see $[4,9,10])$. The ambiguous or situation-dependent relations between environmental quality and economic growth and the inability of economic growth theory for properly explaining these observed phenomena implies the necessity that more comprehensive theories are needed.

Economic growth often implies worsened environmental conditions. Growth also implies a higher material standard of living which will, through the demand for a better environment induces changes in the structure of the economy to improve environment. As a society accumulates more capital and makes progresses in technology, more resources may be used to protect environment. Tradeoffs between consumption and pollution have been extensively analyzed since the publication of the seminal papers by $[11,12]$. Issues related to interdependence between economic growth and environment 
have been examined from different perspectives. This paper is concentrated on tradeoffs between economic growth, consumption, and pollution. Pearson [13] classifies determinants of the environmental quality into demand and supply. The supply side includes the population, levels of economic activities, structures of production and consumption, efficiencies, use of different fuels and materials, and external factors. The demand side includes the price of environmental quality, preference, and information and its acquisition. As reviewed by [7], most studies of the environmental change take account of either supply side or demand side, but not both within a single analytical framework. As both production and consumption pollute environment, it is important to take account of all these effects within a compact framework.

This study attempts to make a contribution to the literature by examining interdependence between savings and dynamics of environment with an alternative approach to consumers' behavior. It is an extension of the growth model with environment proposed by [14]. It is similar to the dynamic model by [15] in many aspects. Like in [15], we allow capital allocation between commodity production and pollution abatement; but different the previous model in which labor is omitted in the economy and neglect possible pollution due to consumption, we allow labor allocation between commodity production and pollution abatement and explicitly treat consumption as a source of pollution. We also use an alternative approach to household behavior. Rather than taking account of environmental action by firms and households, this study introduces environmental taxation on firms (outputs), wealth income, and wage income. There are models with environmental tax incidence (see, $[16,17])$. Our approach differs from the traditional approaches mainly with regard to how the environmental taxation affects behavior of households. The paper is organized as follows. Section 2 introduces the basic model with wealth accumulation and environmental dynamics. Section 3 examines dynamic properties of the model and simulates the model, identifying the existence of a unique equilibrium and checking the stability conditions. Section 4 studies effects of changes in some parameters on the system. Section 5 concludes the study. The appendix proves the analytical results in Section 3.

\section{The Basic Model}

The economy has one production sector and one environmental sector. Most aspects of the production sector are similar to the standard one-sector growth model (see $[18,19])$. It is assumed that there are only one (durable) good and one pollutant in the economy under consideration. It should be noted that the traditional approach in the environmental economics usually assumes a single pollutant. Nevertheless, many production processes are accompanied by the emissions of multiple pollutants. For instance, [20] develop a model of optimal abatement with multiple pollutants. The pollutants can be either technological substitutes or complements (see [21-23]). Households own capital of the economy and distribute their incomes to consume the commodity and to save. Exchanges take place in perfectly competitive markets. We assume a homogenous and fixed population. The labor force is distributed between the two sectors under perfect completion in labor market. We select commodity to serve as numeraire (whose price is normalized to 1 ), with all the other prices being measured relative to its price.

\subsection{The Production Sector}

In the literature of environmental economics, pollution may affect productivity through the channel that pollution directly affects production technology or the productivity of any input (see [24-27]). We assume that production is to combine labor force, $N_{i}(t)$ and physical capital, $K_{i}(t)$. We add environmental impact to the conventional production function. The production function is specified as follows

$$
\begin{aligned}
F_{i}(t)= & A_{i} \Gamma_{i}(E) K_{i}^{\alpha_{i}}(t) N_{i}^{\beta_{i}}(t), \\
& A_{i}, \alpha_{i}, \beta_{i}>0, \alpha_{i}+\beta_{i}=1,
\end{aligned}
$$

where $F_{i}(t)$ is the output level of the production sector at time $t, \Gamma_{i}(E)$ is a function of the environmental quality measured by the level of pollution, $E(t)$ and $A_{i}, \alpha_{i}$ and $\beta_{i}$ are parameters. It is reasonable to assume that productivity is negatively related to the pollution level, i.e., $\Gamma_{i}(E) \leq 0$.

Markets are competitive; thus labor and capital earn their marginal products. As the environmental quality is given for individuals firms, it is not a decision variable for firms. The rate of interest, $r(t)$ and wage rate, $w(t)$, are determined by markets. The marginal conditions are given by

$$
r(t)+\delta_{k}=\frac{\alpha_{i}\left(1-\tau_{i}\right) F_{i}(t)}{K_{i}(t)}, w(t)=\frac{\beta_{i}\left(1-\tau_{i}\right) F_{i}(t)}{N_{i}(t)},
$$

where $\delta_{k}$ is the fixed depreciation rate of physical capital and $\tau_{i}$ is the fixed tax rate, $0<\tau_{i}<1$.

\subsection{Consumer Behaviors}

Consumers choose how much to consume and how much to save. We apply an alternative approach to behavior of the household. We denote per capita wealth by $k(t)$, 
where $k(t) \equiv K(t) / N$. Per capita current income from the interest payment $r(t) k(t)$ and the wage payment $w(t)$ is given by

$$
y(t)=\left(1-\tau_{k}\right) r(t) k(t)+\left(1-\tau_{w}\right) w(t)
$$

where $\tau_{k}$ and $\tau_{w}$ are respectively the tax rates on the interest payment and wage income. We call $y(t)$ the current income. The per capita disposable income is

$$
\hat{y}(t)=y(t)+k(t)
$$

The disposable income is used for saving and consumption. At each point of time, a consumer would distribute the total available budget among saving, $s(t)$ and consumption of the commodity, $c(t)$. The budget constraint is given by

$$
\left(1+\tau_{c}\right) c(t)+s(t)=\hat{y}(t)
$$

where $\tau_{c}$ is the tax rate on the consumption. It should be noted that this study does not explicitly take account of consumers' awareness of environment. For instance, consumers may prefer to environment-friendly goods when their living conditions are changed. With regard to how much money the economic agent should spend on environmental improvement, [28] holds that at a lower level of pollution, the representative agent does not care much about environment and spends his resource on consumption; however, as the environment becomes worse and income becomes higher, more capital will be used for environmental improvement. We may take account of changes in consumers' behavior, for instance, by assuming that the representative consumer spends a proportion of the disposable income on environment or the tax rate on the consumer's consumption is explicitly related to income and consumption level.

At each point of time, consumers decide $s(t)$ and $c(t)$. For simplicity of analysis, we specify the utility function as

$U(t)=c^{\xi_{0}}(t) s^{\lambda_{0}}(t) E^{-\chi_{0}}(t), \xi_{0}, \lambda_{0}, \chi_{0}>0$,

where $\xi_{0}$ is called the propensity to consume and $\lambda_{0}$ the propensity to own wealth. A detailed explanation of the approach and its applications to different problems of economic dynamics are provided in [14]. It should be noted that in $[29,30]$, it is assumed that utility depends negatively on pollution, which is a side product of the production process. As reviewed by Munro [31], "environmental economics has been slow to incorporate the full nature of the household into its analytical structures. ... An accurate understanding household behavior is vital for environmental economics." Our approach to household behavior is still over-simplified as, for instance, we analyze an economy with a single good and a single pollutant. We will deal with household behavior more realistically by, for instance, introducing multiple goods into the utility functions and each good has distinct features with regard o pollution (and may be subject to different environmental policies). We may also take account of family structure in the modeling. How to take account of different aspects of reality is illustrated by [14], even though it may be difficult to construct practically meaningful and analytically tractable models.

For the representative consumer, wage rate $w(t)$ and rate of interest $r(t)$ are given in markets and wealth $k(t)$ is predetermined before decision. Maximizing $U(t)$ subject to budget constraint (4) yields

$$
c(t)=\xi \hat{y}(t), \quad s(t)=\lambda \hat{y}(t),
$$

where

$$
\xi \equiv \frac{\rho \xi_{0}}{1+\tau_{c}}, \lambda \equiv \rho \lambda_{0}, \quad \rho \equiv \frac{1}{\xi_{0}+\lambda_{0}} .
$$

In this study, the pollution does not directly affect the household's decision. This occurs because we omit, for instance, space in our model at this initial stage. If we explicitly introduce urban structure, then the pollution will directly affect households' decisions through the decision on choice of residential location of households.

We now find dynamics of capital accumulation. According to the definition of $s(t)$ the change in the household's wealth is given by

$$
\dot{k}(t)=s(t)-k(t) \text {. }
$$

The equation simply states that the change in wealth is equal to saving minus dissaving. As output of the production sector is equal to the sum of the level of consumption, the depreciation of capital stock and the net savings, we have

$$
C(t)+S(t)-K(t)+\delta_{k} K(t)=F_{i}(t),
$$

where $C(t)$ is the total consumption, $S(t)-K(t)+$ $\delta_{k} K(t)$ is the sum of the net saving and depreciation. We have

$C(t)=c(t) N, S(t)=s(t) N$.

Let $N$ and $K(t)$ stand respectively for the (fixed) the population and total capital stock. The labor force is allocated between the two sectors. As full employment of labor and capital is assumed, we have

$$
K_{i}(t)+K_{e}(t)=K(t), \quad N_{i}(t)+N_{e}(t)=N .
$$

We now describe dynamics of the stock of pollutants, $E(t)$. We assume that pollutants are created both by production and consumption. We specify the dynamics of the stock of pollutants as follows

$$
\dot{E}(t)=\theta_{f} F_{i}(t)+\theta_{c} C(t)-Q_{e}(t)-\theta_{0} E(t),
$$

in which $q_{f}, q_{c}$, and $q_{0}$ are positive parameters and 


$$
Q_{e}(t)=A_{e} \Gamma_{e}(E) K_{e}^{\alpha_{e}}(t) N_{e}^{\beta_{e}}(t), A_{e}, \alpha_{e}, \beta_{e}>0,(10)
$$

where $N_{e}(t)$ and $K_{e}(t)$ are respectively the labor force and capital stocks employed by the environmental sector, $A_{e}, \alpha_{e}$ and $\beta_{e}$ are positive parameters, and $\Gamma_{e}(E)(\geq 0)$ is a function of $E$. The term $\theta_{f} F$ means that pollutants that are emitted during production processes are linearly positively proportional to the output level (see [32]). The parameter, $\theta_{c}$ means that in consuming one unit of the good the quantity $\theta_{c}$ is left as waste. In [33-35], consumption degrades environment. The parameter $\theta_{c}$ depends on the technology and environmental sense of consumers. The parameter $\theta_{0}$ is called the rate of natural purification. The term $\theta_{0} E$ measures the rate that the nature purifies environment. The term, $K_{e}^{\alpha_{e}} N_{e}^{\beta_{e}}$ in $Q_{e}$ means that the purification rate of environment is positively related to capital and labor inputs. The function, $\Gamma_{e}(E)$ implies that the purification efficiency is dependent on the stock of pollutants. It is not easy to generally specify how the purification efficiency is related to the scale of pollutants. For simplicity, we specify $\Gamma_{e}$ as follows $\Gamma_{e}(E)=\theta_{e} E^{v}$, where $\theta_{e}>0$ and $v>0$ are parameters.

We now determine how the government determines the number of labor force and the level of capital employed for purifying pollution. We assume that all the tax incomes are spent on environment. The government's tax incomes consist of the tax incomes on the production sector, consumption, wage income and wealth income. Hence, the government's income is given by

$$
Y_{e}(t)=\tau_{i} F_{i}(t)+\tau_{c} C(t)+\tau_{w} N w(t)+\tau_{k} r(t) K(t) .
$$

Ono [36] introduces tax on the producer and uses the tax income for environmental improvement in the traditional neoclassical growth theory. For simplicity, we assume that the government's income is used up only for the environmental purpose. As there are only two input factors in the environmental sector, the government budget is given by

$$
\left(r(t)+\delta_{k}\right) K_{e}(t)+w(t) N_{e}(t)=Y_{e}(t) .
$$

We need an economic mechanism to analyze how the government distributes the tax income. We assume that the government will employ the labor force and capital stocks for purifying environment in such a way that the purification rate achieves its maximum under the given budget constraint. The government's optimal problem is given by

$$
\begin{aligned}
& \quad \operatorname{Max} Q_{e}(t) \text { s.t.: } \\
& \left(r(t)+\delta_{k}\right) K_{e}(t)+w(t) N_{e}(t)=Y_{e}(t) .
\end{aligned}
$$

The optimal solution is given by $\left(r(t)+\delta_{k}\right) K_{e}(t)=\alpha Y_{e}(t), w(t) N_{e}(t)=\beta Y_{e}(t),(13)$

where

$$
\alpha \equiv \frac{\alpha_{e}}{\alpha_{e}+\beta_{e}}, \quad \beta \equiv \frac{\beta_{e}}{\alpha_{e}+\beta_{e}} .
$$

We have thus built the dynamic model. We now examine dynamics of the model.

\section{The Dynamics and Its Properties}

This section examines dynamics of the model. First, we introduce a new variable by $z(t) \equiv K_{i}(t) / K_{e}(t)$. We now show that the dynamics of the economic system can be expressed by the two-dimensional differential equations system with $z(t)$ and $E(t)$ as the variables.

\section{Lemma 1}

The economy is governed by the 2-dimensional differential equations

$$
\dot{z}=\Lambda_{z}(z, E), \quad \dot{E}=\Lambda_{e}(z, E),
$$

where the functions in (14) are only dependent on $z(t)$ and $E(t)$ which are given in the appendix. Moreover, all the other variables can be determined as functions of $z(t)$ and $E(t)$ at any point of time by the following procedure: $K$ by (A6) $\rightarrow K_{i}$ and $K_{e}$ by (A2) $\rightarrow N_{i}$ and $N_{e}$ by (A3) $\rightarrow F_{i}$ by (1) $\rightarrow r$ and $w$ by (2) $\rightarrow Q_{e}$ by (10) $\rightarrow y$ by (3) $\rightarrow c$ and $s$ by (11).

As the expressions of the analytical results are tedious, for illustration we specify the parameter values and simulate the model. We specify the parameters as follows

$$
\begin{aligned}
& \Gamma_{i}=E^{-b_{i}}, \Gamma_{e}=E^{-b_{e}}, b_{i}=0.1, b_{e}=0.2, N_{0}=5, \\
& \alpha_{i}=0.3, A_{i}=1, \quad \alpha_{e}=0.7, \quad \beta_{e}=0.7, A_{e}=0.5, \\
& \lambda_{0}=0.6, \quad \xi_{0}=0.15, \quad \delta_{k}=0.05, \theta_{f}=0.1, \\
& \theta_{c}=0.1, \quad \theta_{0}=0.05, \quad \tau_{c}=\tau_{i}=\tau_{k}=\tau_{w}=0.05 . \quad(15)
\end{aligned}
$$

The population is fixed at 5 . The propensity to save is much higher than the propensity to consume the commodity and the propensity to consume the renewable resource. Under (15), the dynamic system has a unique equilibrium point. The equilibrium values are given as in (16)

$$
\begin{aligned}
& K=25.55, \quad E=0.78, \quad F_{i}=7.28, \quad Q_{e}=1.30, \\
& N_{i}=4.68, \quad N_{e}=0.32, \quad K_{i}=18.68, \\
& K_{e}=6.87, \quad r=0.061, \quad w=1.03, \quad c=1.22 .
\end{aligned}
$$

The two eigenvalues are -0.55 and -0.14 . This guarantees the stability of the steady state. Hence, the dynamic system has a unique stable steady state.

\section{Lemma 2}

If the parameter values are specified as in (15), the 
dynamic system has a unique stable equilibrium.

With the initial conditions, $z(0)=3.0$ and $E(0)=$ 0.5 , we plot the motion of the system as in Figure 1. The length of the simulation period is 40 , which is long enough for the system approach its unique equilibrium point. The national capital stock and capital stocks employed by the two sectors are increased over time. The disposable income, current income, the output level of the industrial sector, the wage rate and consumption level are all increased. The labor force shifts from the production sector to the environmental sector over time. The rate of interest falls as the capital intensity is increased. The level of pollution rises initially and then falls.

As far as the standard one-sector neoclassical growth theory (i.e., the Solow model) is concerned, our model predicts the same growth pattern. Nevertheless, our economic structure contains environmental aspects. We now show that our model identifies the environmental Kuznets curve. To see clearly the relation between the current income and the environmental change, we plot the two variables in 20 years as in Figure 2. It should be remarked that in this study we assume that the environmental tax rates are not dependent on the economic and environmental conditions. It is more realistic to assume that the tax rates are related to these conditions. It expected that within this modeling framework (without other externalities and endogenous knowledge), if the tax rates are, for instance, positively related to the economic conditions, then the equilibrium level of pollution should be lower and it would take less time for the system to start experiencing environmental improvement.

\section{Comparative Dynamic Analysis}

This section examines effects of changes in some parameters on the motion of the economic system. First, we study the case that all the parameters, except the speed that consumption pollutes the environment, are the same as in (15). We increase the parameter in the following way: $\theta_{c}: 0.1 \Rightarrow 0.12$. The simulation results are demonstrated in Figure 3. In the plots, a variable $\bar{\Delta} x_{j}(t)$ stands for the change rate of the variable $x_{j}(t)$ in percentage due to changes in the parameter value. We will use the symbol $\bar{\Delta}$ with the same meaning when we analyze other parameters. The rise in the speed that consumption pollutes the environment, reduces the national and two sector's capital stocks, wage rate and level of the consumption good, the interest rate. The labor force employed by the environmental sector rises initially and then approaches to the same equilibrium value as before. The level of pollution is increased over time. Hence, if the consumers have less awareness of environment, all aspects of the living conditions are deteriorated. When the consumers pollute more environment with same level
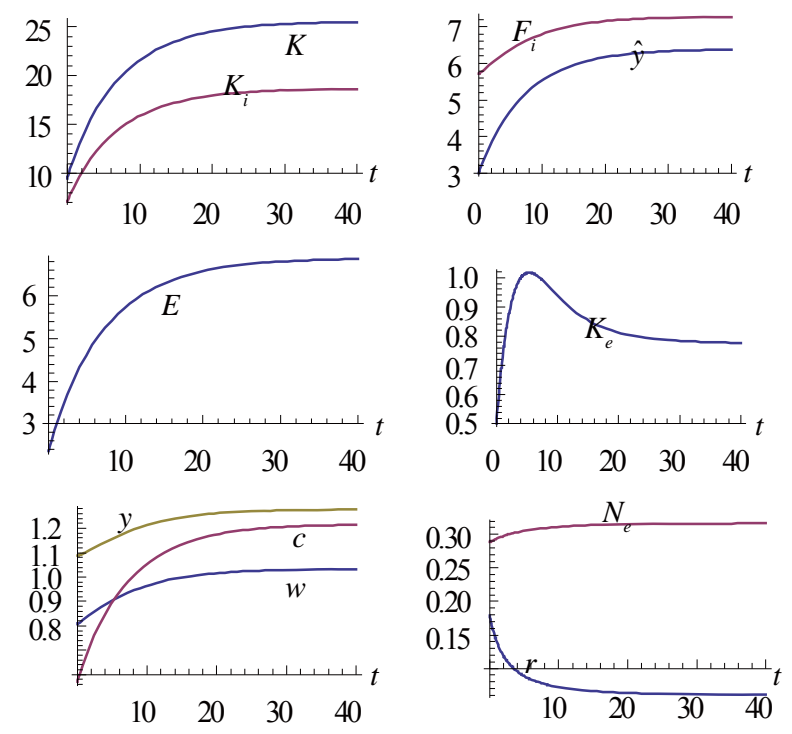

Figure 1. Motion of the Economic System.

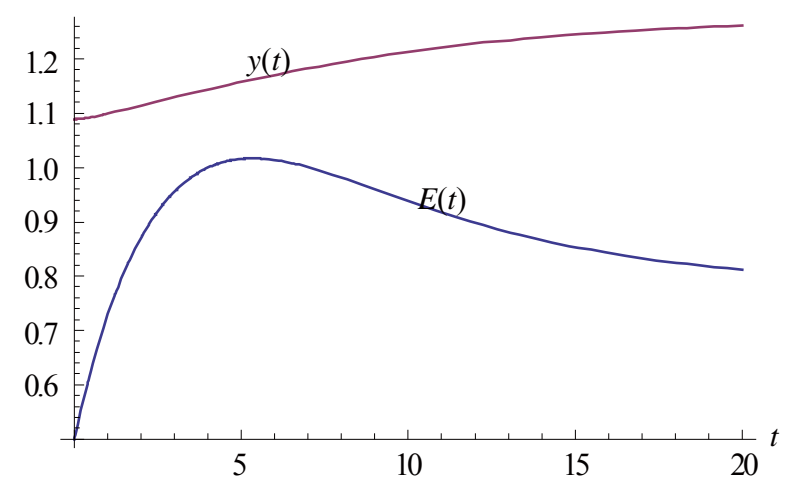

Figure 2. The Environmental Kuznets Curve.

of consumption, there are more pollutants. As the environmental condition is deteriorated, the productivity becomes lower, which leads to less capital and lower wage rate. As the dynamic system has a unique stable equilibrium, it approaches its steady state.

We now raise the propensity to save the following way: $\lambda_{0}: 0.6 \Rightarrow 0.62$. The simulation results are demonstrated in Figure 4. The effects of a rise in the propensity to save are quite similar as the effects of a rise in the saving rate in the Solow model. The output of the production sector, wage rate, capital stocks and income are increased. It should be noted that different from the Solow model, the short-term as long-term consumption level is increased in our model. This occurs partly because as the consumers save more out of the income, capital is increased. As capital is increased, some workers shift their jobs in the environmental sector to the production sector. Hence, although the rise in the propensity to save tends to reduce consumption, the net effect is to raise consumption. The environment is im- 
proved over time mainly because a higher propensity to save leads to increases in the environmental sector total effort, $Q_{e}(t)$.

If we raise the environmental tax rate on consumption as follows: $\tau_{c}: 0.05 \Rightarrow 0.07$, then the dynamic path of the economic system is shifted as illustrated in Figure 5. Initially, the economic system suffers and the environment deteriorates. But soon the economic conditions are improved and the environment becomes better.

\section{Concluding Remarks}

This study built a model which describes a dynamic interdependence among physical accumulation, environ-
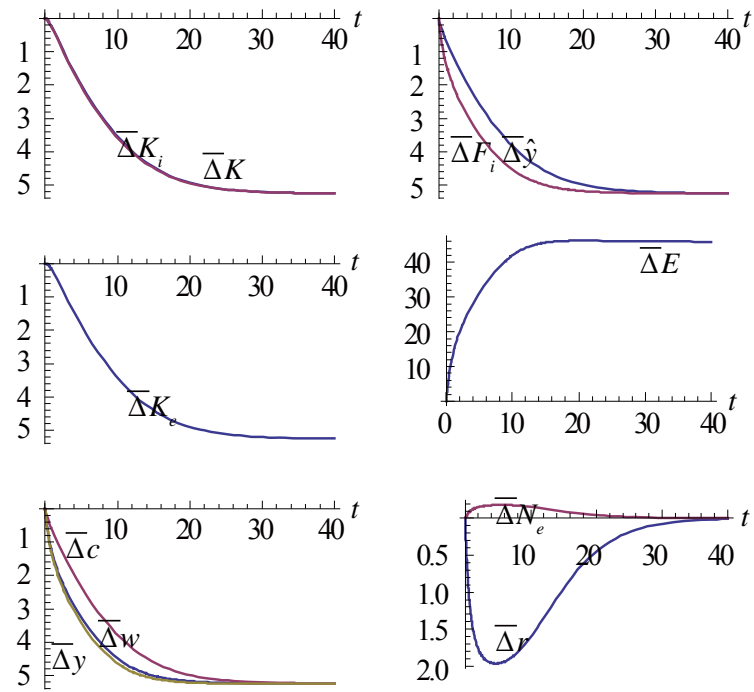

Figure 3. Consumption Pollutes the Environment More Rapidly.
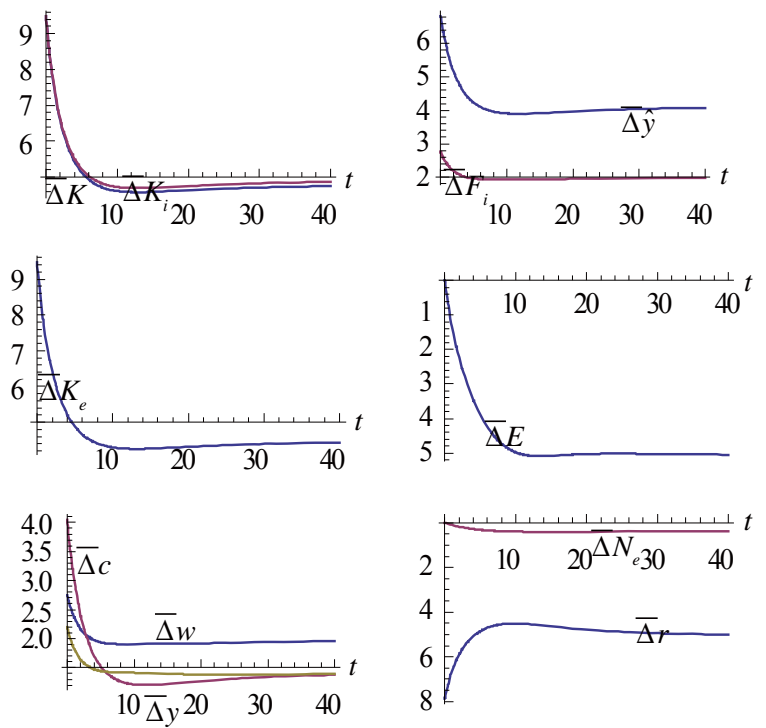

Figure 4. A Rise in the Propensity to Save.
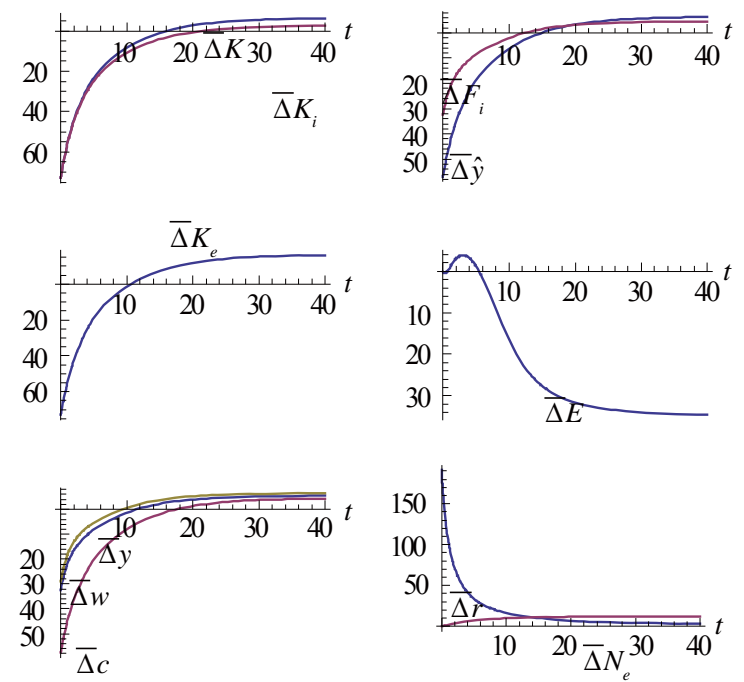

Figure 5. A Rise in the Environmental Tax Rate on Consumption.

mental change and division of labor under perfect competition with environmental taxes on production, wealth income, wage income and consumption. We synthesized the growth mechanism in the neoclassical growth theory and the environmental dynamics in traditional models of environmental economics within a comprehensive framework with an alternative approach to household behavior. We simulated the model to demonstrate existence of equilibrium points and motion of the dynamic system. The simulation demonstrates some dynamics which can be predicted neither by the neoclassical growth theory Solow model nor by the traditional economic models of environmental change. We may extend the model in some directions. For instance, we may introduce leisure time as an endogenous variable. Munro [31] correctly points out: "In the unitary model, the household acts as if it is a single individual maximizing a single utility function in the face of one budget constraint. It is a simplifying modeling assumption that is widely used in most branches of economics, but it is wrong. The fact that the unitary model is inaccurate is well-known and has been known for many years now." It is important to take account of family structure as well as economic structure in analyzing relations between growth and environmental change. As demonstrated by [37], consumers voluntarily pay significant price premiums to acquire environmental attributes in environment-friendly products. Whether fast economic growth will hurt or improve environmental quality is also dependent on the pollutant (see [9]). We may analyze this issue by introducing multiple goods into the model. Another important extension of this research is to study dynamic interdependence among economic growth, health and environment (see $[32,38-40])$. 


\section{Acknowledgments}

The author is grateful to important comments of the anonymous referee and the effective help from Editorial Assistant Shirley Zhou. Financial support under "APU Academic Research Subsidy", is gratefully acknowledged. The usual disclaimer applies.

\section{References}

[1] B. Copeland and S. Taylor, "Trade, Growth and the Environment," Journal of Economic Literature, Vol. 42, No. 1, 2004, pp. 7-71. doi:10.1257/002205104773558047

[2] D. I. Stern, "The Rise and Fall of the Environmental Kuznets Curve," World Development, Vol. 32, No. 8, 2004, pp. 1419-1439. doi:10.1016/j.worlddev.2004.03.004

[3] S. Dasgupta, K. Hamilton, K.D. Pandey and D. Wheeler, "Environment during Growth: Accounting for Governance and Vulnerability," World Development, Vol. 34, No. 9, 2006, pp. 1597-1611. doi:10.1016/j.worlddev.2005.12.008

[4] T. Tsurumi and S. Managi, "Decomposition of the Environmental Kuznets Curve: Scale, Technique, and Composition Effects," Environmental Economics and Policy Studies, Vol. 11, 2010, pp. 19-36. doi:10.1007/s10018-009-0159-4

[5] G. M. Grossman, "Pollution and Growth: What Do We Know?" In: I. Goldin and L.A. Winters, Eds., The Economics of Sustainable Development, Cambridge University Press, Cambridge, 1995.

[6] W. Brock and M.S. Taylor, "Economic Growth and the Environment: A Review of Theory and Empirics," In: S. Durlauf and P. Aghion, Eds., The Handbook of Economic Growth, Elsevier, Amsterdam, 2006.

[7] M. Kijima, K. Nishide, K., and A. Ohyama, "Economic Models for the Environmental Kuznets Curve: A Survey," Journal of Economic Dynamics \& Control, Vol. 34, 2010, pp. 1187-201. doi:10.1016/j.jedc.2010.03.010

[8] S. Kuznets, "Economic Growth and Economic Inequality," American Economic Review, Vol. 45, 1955, pp. 128.

[9] S. Dinda, "Environmental Kuznets curve hypothesis: A survey," Ecological Economics, Vol. 49, No. 4, 2004, pp. 431-455. doi:10.1016/j.ecolecon.2004.02.011

[10] S. Managi, Technological Change and Environmental Policy: A Study of Depletion in the Oil and Gas Industry. Cheltenham: Edward Elgar, 2007.

[11] G. C. Plouder, "A Model of Waste Accumulation and Disposal," Canadian Journal of Economics, Vol. 5, No. 1, 1972, pp. 119-125. doi:10.2307/133997

[12] B. A. Forster, "Optimal Consumption Planning in a Polluted Environment," Economic Record, Vol. 49, 1973, pp. 534-545. doi:10.1111/j.1475-4932.1973.tb01954.x

[13] P. J. Pearson, "Energy, Externalities and Environmental Quality: Will Development Cure the Ills It Creates?" Energy Studies Review, Vol. 6, No. 3, 1994, pp. 199-216.
[14] W. B. Zhang, "Economic Growth Theory," Ashgate, London, 2005.

[15] S. Dinda, "A Theoretical Basis for the Environmental Kuznets Curve: Turning Point and Public Policy," Environmental and Resource Economics, Vol. 36, 2005, pp. 15-34.

[16] V. T. Rapanos, "A Note on Externalities and Taxation," Canadian Journal of Economics, Vol. 25, 1992, pp. 226232. doi:10.2307/135721

[17] V. T. Rapanos, "The Effects of Environmental Taxes on Income Distribution," European Journal of Political Economy, Vol. 11, No. 3, 1995, pp. 487-501. doi:10.1016/0176-2680(95)00007-K

[18] E. Burmeister and A.R. Dobell, "Mathematical Theories of Economic Growth," Collier Macmillan Publishers, London, 1970.

[19] R. J. Barro and X. Sala-i-Martin, "Economic Growth," McGraw-Hill, Inc., New York, 1995.

[20] U. Moslener and T. Requate, "Optimal Abatement in Dynamic Multi-pollutant Problems When Pollutants Can Be Complements or Substitutes," Journal of Economic Dynamics \& Control, Vol. 31, No. 7, 2007, pp. 22932316. doi:10.1016/j.jedc.2006.03.009

[21] R. Repetto, "The Policy Implications of Non-convex Environmental Damages: A Smog Control Case," Journal of Environmental Economics and Management, Vol 14, 1987, pp. 13-29. doi:10.1016/0095-0696(87)90002-7

[22] J. E. Leighter, "Weather-Induced Changes in the Trade-of between $\mathrm{SO}_{2}$ and $\mathrm{NO}_{\mathrm{x}}$ at Large Power Plants," Energy Economics, Vol. 21, No. 3, 1999, pp. 239-259. doi:10.1016/S0140-9883(98)00018-8

[23] W. D. Nordhaus, "Warming the World, Economic Models of Global Warming," MIT Press, Cambridge, 2000.

[24] A. Grimaud, "Pollution Permits and Sustainable Growth in a Schumpeterian Model," Journal of Environmental Economics and Management, Vol. 38, No. 3, 1999, pp. 249-266. doi:10.1006/jeem.1999.1088

[25] H. Chao and S. Peck, "Greenhouse gas abatement: how much? And who pays?," Resource and Energy, Vol. 67, 2000, pp. 1-24.

[26] R. Gradus and S. Smulders, "The Trade-off between Environmental Care and Long-Term Growth-Pollution in Three Prototype Growth Models," Journal of Economics, Vol. 58, No. 1, 1996, pp. 25-51. doi:10.1007/BF01234800

[27] T. Ono, "Emission Permits on Growth and the Environment," Environmental and Resources Economics, Vol. 20, 2002, pp. 75-87. doi:10.1023/A:1014595532338

[28] T. M. Selden, and D. Song, "Neoclassical Growth, the J Curve for Abatement and the Inverted U Curve for Pollution," Journal of Environmental Economics and Management, Vol. 29, 1995, pp. 162-168. doi:10.1006/jeem.1995.1038

[29] A. Balcao, "Endogenous Growth and the Possibility of Eliminating Pollution," Journal of Environmental Economics and Management, Vol. 42, 2001, pp. 360-373. doi:10.1006/jeem.2000.1159 
[30] M. Nakada, "Does Environmental Policy Necessarily Discourage Growth?" Journal of Economics, Vol. 81, 2004, pp. 249-268. doi:10.1007/s00712-002-0609-y

[31] A. Munro, "Introduction to the Special Issue: Things We Do and Don'T Understand about the Household and the Environment," Environmental and Resources Economics, Vol. 43, No. 1, 2009, pp. 1-10. doi:10.1007/s10640-009-9284-6

[32] M. Gutiérrez, "Dynamic Inefficiency in an Overlapping Generation Economy with Pollution and Health Costs," Journal of Public Economic Theory, Vol. 10, No. 4, 2008, pp. 563-594. doi:10.1111/j.1467-9779.2008.00377.x

[33] A. John, R. Pecchenino, Schimmelpfenning and S. Schreft, "Short-Lived Agents and the Long-Lived Environment," Journal of Public Economics, Vol. 58, No. 1, 1995, pp. 127-141. doi:10.1016/0047-2727(94)01459-2

[34] A. John and R. Pecchenino, "An Overlapping Generation Model of Growth and the Environment," The Economic Journal, Vol. 104, No. 427, 1994, pp. 1393-1410. doi: $10.2307 / 2235455$

[35] F. Prieur, "The Environmental Kuznets Curve in a World of Irreversibility," Economic Theory, Vol. 40, No. 1, 2009, pp. 57-90. doi:10.1007/s00199-008-0351-y

[36] T. Ono, "Environmental Tax Policy and Long-Run Economic Growth," The Japanese Economic Review, Vol. 53, 2003, pp. 202-217.

[37] S. F. Hamilton and D. Zilberman, "Green Markets, Eco-certification, and Equilibrium Fraud," Journal of Environmental Economics and Management, Vol. 52, No. 3, 2006, pp. 627-644. doi:10.1016/i.jeem.2006.05.002

[38] R. C. III. Williams, "Environmental Tax Interaction When Pollution Affects Health or Productivity," Journal of Environmental Economics and Management, Vol. 87, 2002, pp. 271-270.

[39] K. K. Tang and J. Zhang, "Health, Education and Life-Cycle Savings in the Development Process," Economic Inquiry, Vol. 45, No. 3, 2007, pp. 615-630. doi:10.1111/j.1465-7295.2007.00020.x

[40] S. Chakraborty, "Endogenous Lifetime and Economic Growth," Journal of Economic Theory, Vol. 116, No. 1, 2004, pp. 119-137. doi:10.1016/j.jet.2003.07.005 


\section{Appendix}

We now show that the dynamics can be expressed by a two-dimensional differential equations system. From (2) and (13), we obtain

$$
\mathrm{z}=\frac{K_{i}}{K_{e}}=\bar{\alpha} \frac{N_{i}}{N_{e}},
$$

where we omit time index and $\bar{\alpha} \equiv \beta_{e} \alpha_{i} / \alpha_{e} \beta_{i}$ By (A1) and (8), we solve

$$
\begin{aligned}
& K_{i}=\frac{z K}{z+1}, \quad K_{e}=\frac{K}{z+1}, \\
& N_{i}=\frac{z N}{z+\bar{\alpha}}, \quad N_{e}=\frac{\bar{\alpha} N}{z+\bar{\alpha}} .
\end{aligned}
$$

From $w N_{e}=\beta Y_{e}$ in (13) and (11), we have $\frac{w N_{e}}{\beta}=\tau_{i} F_{i}+\tau_{c} N \xi \hat{y}+\tau_{w} N w+\tau_{k} r K$.

where we use $c=\xi \hat{y}$. Insert the definition of $\hat{y}$ in the above equation

$$
\begin{aligned}
& \left(\frac{N_{e}}{\beta}-\tau_{c} \xi \bar{\tau}_{w} N-\tau_{w} N\right) w=\tau_{i} F_{i}+\tau_{c} \xi K+ \\
& \left(\bar{\tau}_{k} \tau_{c} \xi+\tau_{k}\right) r K,
\end{aligned}
$$

where $\bar{\tau}_{k} \equiv 1-\tau_{k}$ and $\bar{\tau}_{w} \equiv 1-\tau_{w}$. Substituting (2) into (A4) yields

$$
\begin{aligned}
& \left(\frac{N_{e}}{\beta}-\tau_{c} \xi \bar{\tau}_{w} N-\tau_{w} N\right) \frac{\beta_{i} \bar{\tau}_{i}}{N_{i}}= \\
& \tau_{i}+\left(\tau_{c} \xi-\tau_{0} \delta_{k}\right) \frac{K}{F_{i}}+\frac{\alpha_{i} \tau_{0} \bar{\tau}_{i} K}{K_{i}},
\end{aligned}
$$

in which $\bar{\tau}_{i} \equiv 1-\tau_{i}$ and $\tau_{0} \equiv \bar{\tau}_{k} \tau_{c} \xi+\tau_{k}$ Substituting (1), (A2) and (A3) into (A5), we solve

$$
K=\Omega(z, E) \equiv\left[\frac{A_{i} \Gamma_{i} \Omega_{0}(z)}{\left(\tau_{c} \xi-\tau_{0} \delta_{k}\right)(z+1)^{\alpha_{i}}}\right]^{1 / \beta_{i}} \frac{N}{z+\bar{\alpha}},
$$

where

$$
\begin{aligned}
\Omega_{0}(z) & \equiv \frac{\beta_{i} \bar{\tau}_{i} \bar{\alpha}}{\beta}-\beta_{i} \bar{\tau}_{i}\left(\tau_{c} \xi \bar{\tau}_{w}+\tau_{w}\right)(z+1) \\
& -\tau_{i} z-\alpha_{i} \tau_{0} \bar{\tau}_{i}(z+1) .
\end{aligned}
$$

We express $K$ as a function of $z(t)$ and $E(t)$. From (A2), $K_{i}$ and $K_{e}$ are functions of $z$. From (A3), $N_{i}$ and $N_{e}$ are functions of $z$. By the following procedure, we can express other variables as functions of $z(t)$ and $E(t)$ at any point of time: $F_{i}$ by (1) $\rightarrow r$ and $w$ by (2) $\rightarrow Q_{e}$ by (10) $\rightarrow \hat{y}$ by (3) $\rightarrow c$ and $s$ by (11). By these results and from (9) we get the following differential equation

$$
\begin{aligned}
\dot{E}(t)= & \Lambda_{e}(z(t), E(t)) \equiv \\
& \theta_{f} F_{i}(t)+\theta_{c} C(t)-Q_{e}(t)-\theta_{0} E(t) .
\end{aligned}
$$

We do not provide explicit expressions of the functions as it is straightforward to do so and the expressions are too tedious. Taking derivatives of (A9) with respect to $t$ yields

$$
\dot{K}=\frac{\partial \Omega}{\partial z} \dot{z}+\Lambda_{e} \frac{\partial \Omega}{\partial E},
$$

where we also use (A7). Multiplying the two sides of (11) with $N$ and using (5), we have

$$
\dot{K}=\lambda N \hat{y}(z, E)-K,
$$

where we use (5). From (A8) and (A9), we solve

$$
\dot{z}=\Lambda_{z}(z, E) \equiv\left[\lambda N \hat{y}(z, E)-K-\Lambda_{e} \frac{\partial \Omega}{\partial E}\right]\left(\frac{\partial \Omega}{\partial z}\right)^{-1} .
$$

We have thus proved Lemma 1. 